\title{
Skin associated problems in working donkeys in three districts of Sidama Zone, Southern Ethiopia
}

\author{
Kassaye Aragaw ${ }^{1 *}$, Abdulaziz Abdella ${ }^{1}$, Amene Fekadu ${ }^{1}$, Asmamaw Kassaye ${ }^{2}$, Bojia \\ Hindebu $^{2}$ and Desie Sheferaw ${ }^{1}$ \\ ${ }^{1}$ Hawassa University, School of Veterinary Medicine, P.O. Box 05, Hawassa, Ethiopia
}

${ }^{2}$ The Donkey Sanctuary, P.O. Box 1055, Addis Ababa, Ethiopia

*Corresponding author: Hawassa University, School of Veterinary Medicine, P.O. Box 05, Hawassa, Ethiopia,Email: kassaye33@yahoo.com

http://dx.doi.org/10.4314/evj.v20i2.8

\begin{abstract}
This study was conducted between November 2010 and April 2011 in 3 districts of Sidama Zone, southern Ethiopia, to estimate the prevalence and identify risk factors influencing occurrences of skin problems in donkeys. A total of randomly selected 384 male donkeys were clinically examined for skin problems. Hypothesized risk factors (age, body condition, use, feeding, housing at night, harness material, harness fitness) were either observed and recorded at the time of clinical examination or collected through semi-structured questionnaire. The overall prevalence of skin problems, taking into consideration harness sores, hyena bite, donkey bite, ectoparasites, epizootic lymphangitis, sarcoid, dermatophytosis, abscess, brand scar and ulcer due to Habronema was 91.9\%. Sores were the most important (82.3\%) skin problems followed by ectoparasites $(22.1 \%)$. The ectoparasites identified in the study were lice (11.2\%), ticks (10.4\%) and mange mites $(1.6 \%)$, with mixed infestation involving lice and ticks in $0.8 \%$ of the donkeys. Body condition, age, harness material and harness fitness were significantly associated with sore prevalence $(P<0.001)$. Donkeys with poor body condition, old donkeys, donkeys with synthetic harness materials and ill-fitting harness had higher prevalence $(P<0.001)$ of sores compared to their counterparts. The study revealed a high prevalence of skin problems in general and sores in particular which suggest profound compromise in welfare and health of the animals and possible neglect by their owners. Efforts should be made to increase the awareness of the community in general and donkey owners in particular towards improving animal welfare and health.
\end{abstract}

Keywords: Skin problems, Donkey, Sore, Lice, Ticks, Ethiopia 


\section{Introduction}

Donkeys are economically very important animals in Ethiopia. The low level development of the road transport network and the rough terrain of the country makes the donkey the most valuable, appropriate and affordable pack animal under the smallholder farming systems of Ethiopia (Alemu Gebrewold et al., 2004). This is why Ethiopia owns the largest donkey population in Africa with 6.4 million in rural sedentary holdings alone (CSA, 2012). Donkeys mainly transport agricultural produce from farm to home and from home to local markets. They are also involved in transporting water and firewood to rural households (Feseha Gebreab et al., 2004; Agajie Tesfaye and Curran, 2005) thereby relieving mainly women from the burden. In general, approximately 0.83 million donkeys in Ethiopia are used for draught purpose (CSA, 2012). In towns, like Hawassa, livelihood of significant number of people depends on carts pulled by donkeys.

However, due to apparent lack of awareness by the owners, donkeys in Ethiopia suffer from a multitude of health and welfare problems (Agajie Tesfaye and Curran, 2005). Skin injuries associated with inappropriate harnessing are among the most important problems in donkeys in Ethiopia (Demelash Biffa and Moges Woldemeskel, 2006). A study conducted in central Ethiopia documented back sore as the most common health problem in donkeys (Agajie Tesfaye and Curran, 2005). Donkeys in Ethiopia also suffer from other skin diseases and ectoparasite infestations (Gobena Ameni, 2006; Beshatu Ferede et al., 2010) with health and welfare implications. Skin afflictions may be major causes of debility and failure to maintain a healthy and effective working life in working donkeys in poorer parts of the world where donkeys often have a short life span because of the rigors of their lives (Knotten belt, 2009). This study was conducted to identify skin associated problems, estimate their prevalence and determine potential risk factors influencing the occurrences of the problems in donkeys in the study area.

\section{Materials and Methods}

\section{Study area}

The study was conducted from November 2010 to April 2011 in 3 localities of Sidama zone namely Hawassa town, Dale and Shebedino districts. Hawassa is the capital city of Southern Nations Nationalities and Peoples Regional 
State (SNNPRS) located about $270 \mathrm{~km}$ south of Addis Ababa. The area is located at $7^{\circ} 3^{\prime}$ latitude North and $38^{\circ} 28^{\prime}$ longitude East at an altitude of 1,680 m.a.s.l. The annual mean rainfall ranges from 800 to $1000 \mathrm{~mm}$ and the mean minimum and maximum annual temperature are $20.1^{\circ} \mathrm{C}$ and $30^{\circ} \mathrm{C}$, respectively. Shebedino and Dale are districts under Sidama zone located 27 and $45 \mathrm{~km}$ south of Hawassa respectively. The topography of Hawassa is flat which makes it convenient to carts drawn by donkeys. The topographies of Dale and Shebedino, however, are characterized mainly by gently rolling slops (Anonymous, 1999). Yiga Alem, the capital of Dale district, is located at $6^{\circ} 45^{\prime}$ North latitude and $38^{\circ} 25^{\prime}$ East longitude at an altitude of about 1777 m.a.s.l. The district has diverse agro-ecological zones, and receives an annual mean average rainfall of $1170 \mathrm{~mm}$ and average annual temperature of $19^{\circ} \mathrm{C}$. The capital of Shebedino district Leku, is located around a coordinate point $6^{\circ} 52^{\prime} \mathrm{N}$ longitude and $38^{\circ} 27^{\prime}$ E latitude at an elevation of 1939 m.a.s.l. The average annual rainfall and temperature of Shebedino district range between 900-1100 $\mathrm{mm}$ and $18-25^{\circ} \mathrm{C}$, respectively (Anonymous, 2004).

\section{Study animals}

The study was conducted on 384 male working donkeys (128 from each locality) randomly selected (with systematic random sampling) from market places, watering points and the Donkey Health and Welfare Project (DHWP) service delivery sites. Most of the donkeys brought to DHWP were for routine de-worming. 
Kassaye Aragaw et al.,

Table 1: Summary of donkeys examined for skin problems in three districts of Sidama zone in southern Ethiopia

\begin{tabular}{|c|c|c|}
\hline Factor & Number & $\%$ \\
\hline Overall & 384 & \\
\hline \multicolumn{3}{|l|}{ Age } \\
\hline Young & 69 & 18.0 \\
\hline Adult & 192 & 50.0 \\
\hline Old & 123 & 32 \\
\hline \multicolumn{3}{|l|}{ Work type } \\
\hline Cart & 195 & 50.8 \\
\hline Pack & 189 & 49.2 \\
\hline \multicolumn{3}{|l|}{ District } \\
\hline Dale & 128 & 33.3 \\
\hline Hawassa & 128 & 33.3 \\
\hline Shebedino & 128 & 33.3 \\
\hline \multicolumn{3}{|c|}{ Body condition score (BCS) } \\
\hline Poor & 105 & 27.3 \\
\hline Moderate & 245 & 63.8 \\
\hline Ideal & 34 & 8.9 \\
\hline \multicolumn{3}{|c|}{ Harness material } \\
\hline Natural & 73 & 19.0 \\
\hline Synthetic & 311 & 81.0 \\
\hline \multicolumn{3}{|l|}{ Harness fitness } \\
\hline Fit & 48 & 12.5 \\
\hline Ill-fit & 336 & 87.5 \\
\hline \multicolumn{3}{|c|}{ Padding material } \\
\hline Natural & 59 & 15.4 \\
\hline Synthetic & 325 & 84.6 \\
\hline \multicolumn{3}{|l|}{ Feeding } \\
\hline Grazing only & 127 & 33.1 \\
\hline Supplemented & 257 & 66.9 \\
\hline \multicolumn{3}{|l|}{ Housing } \\
\hline Indoor & 349 & 90.9 \\
\hline Outdoor & 35 & 9.1 \\
\hline
\end{tabular}




\section{Data collection}

Questionnaire and physical examination of the donkeys were used to collect data. Information regarding age (when it is known to the respondent), work type/use (pack, cart), sheltering at night (indoor, outdoor) and feeding (grazing alone, supplementation) were collected using semi-structured questionnaire. Information regarding harness material, padding material and harness fitness was either directly observed or obtained through interviews using semi-structured questionnaire. Harness and padding materials made up of natural fibers such as cotton, sisal and enset (Ensete ventricosum) fibers were recorded as natural while those made up of materials such as plastics, nylon, polypropylene and used tires were considered synthetic. Body condition of the animals was recorded (into poor, moderate and ideal as there were no donkeys with fat and obese conditions) at the time of physical examination based on the guidelines of NEWC (2009). Age was determined using dentition (Crane, 1997) and was categorized into young $(<5 \mathrm{yrs})$, adult (5-15 yrs) and old ( $>15 \mathrm{yrs})$ as it takes the donkey 4 to 5 years to reach its full size (Jones, 2005).

\section{Clinical and laboratory examination}

\section{History and physical examination}

The entire skin of the animals was thoroughly inspected and palpated for the presence of lesions. Causes for injuries were requested and recorded. For animals showing signs of some skin problems, owners or attendants were asked about presence or absence of pruritis, and duration of the condition and its progress. The types of lesions and their bodily distribution were recorded. According to the observed clinical signs samples were collected for confirmation of dermatophytosis, epizootic lymphangitis and mange. Ticks and lice were collected for species identification.

\section{Lice and mites}

Skin debris and hair particles were combed into plastic container or onto stiff cardboard using stiff brush (tooth brush) for all donkeys presented with history of pruritis for detection of superficial parasites (Chorioptes, lice). The samples were placed into Petri dish and examined under stereomicroscope (Scott and Miller, 2001). 
For the diagnosis of burrowing and follicular mites multiple skin scrapings were collected from the edges of new lesions from cases presented with alopecia, itching and erythematous lesions according to Scott and Miller (2001). Briefly, after removing coat hair by clipping, the area was lightly moistened with liquid paraffin and scraping of the skin was continued until capillary bleeding was produced. A few drops of liquid paraffin were added to the scraped material on microscope slide and a cover slip was placed on the material to be examined. The slides were scanned under low power to observe the movement of mites if they were alive and also examined under higher power for identification of the mites (Knotenbelt, 2009). Lice and mites were identified to genus level based on their morphological characteristics (Urquhart et al., 1996; Wall and Shearer, 1997).

\section{Ticks}

Ticks were manually collected by searching on different regions of the animals' body. Attention was given to base of the tail, ear, perineum, sternum, scrotal area and the belly. The ticks were carefully collected and placed in universal bottles containing $70 \%$ ethyl alcohol and were later examined under stereomicroscope and identified to genus level using morphological features according to Walker et al. (2003).

\section{Dermatophytes}

Bunches of abnormal and broken hairs and scrapings from the periphery of active lesions were collected on a clean piece of paper. Small amount of the collected scrapings were placed on a clean glass slide and few drops of $10 \%$ $\mathrm{KOH}$ were added and covered with a cover slip. The slide was gently heated for 15 to 20 seconds to clear the debris. The preparation was examined under both low and high power dry objectives of a light microscope for the presence of fungal elements (Knotenbelt, 2009).

\section{Epizootic lymphangitis}

Impression smear of exudate from epizootic lymphangitis suspected lesions were examined using direct microscopy for oval double-contoured yeast (Quinn et al., 1999). 


\section{Data analyses}

The data collected were entered in Microsoft Excel spread sheet and all analyses were made using STATA statistical software release 9.0 (Stata Corp. College Station, TX). Association of potential risk factors (district, housing at night, harness material, harness fitness, padding material, work type, body condition score (BCS), age) with response variables (sore, ectoparasites, sarcoid, BCS) was evaluated using Chi-square test. The significant level for statistical tests was set to $P<0.05$.

\section{Results}

Most of the donkeys (90.9\%) included in the study were housed indoor during the night and about two third (66.9\%) were supplemented on top of grazing. Only $8.9 \%$ of the donkeys had ideal body condition while $63.8 \%$ and $27.3 \%$ had moderate and poor body condition, respectively. Almost half of the donkeys (50.8\%) studied were used to pull cart and the rest half (49.2\%) were used as pack animals. Most of the harness (81.0\%) and padding (84.6\%) were made up of synthetic materials and most harnesses $(87.5 \%)$ were not properly fitting to the body of the donkeys (Table 1).

Old age, above 15 years, use of donkey for cart and keeping donkeys mainly on grazing were associated $(P<0.05)$ with poor body condition. There was no significant difference $(P>0.05)$ in the body condition of donkeys among the 3 districts and between types of housing at night (Table 2). 
Kassaye Aragaw et al.,

Table 2: Body condition of working donkeys by age, work type, district and feeding in Sidama zone, southern Ethiopia

\begin{tabular}{|c|c|c|c|c|c|c|}
\hline \multirow[t]{2}{*}{ Factor } & \multirow[t]{2}{*}{ Category } & \multirow[t]{2}{*}{$\mathbf{N}$} & \multicolumn{3}{|c|}{ Body condition } & \multirow[b]{2}{*}{$P$ value } \\
\hline & & & Poor & Moderate & Ideal & \\
\hline \multirow[t]{3}{*}{ Age } & Young & 69 & $6.7 \%$ & $20.8 \%$ & $32.4 \%$ & 0.000 \\
\hline & Adult & 192 & $42.9 \%$ & $51.3 \%$ & $50.0 \%$ & \\
\hline & Old & 123 & $50.5 \%$ & $26.1 \%$ & $17.6 \%$ & \\
\hline \multirow[t]{2}{*}{ Work type } & Cart & 195 & $61.0 \%$ & $48.6 \%$ & $35.3 \%$ & 0.018 \\
\hline & Pack & 189 & $39.0 \%$ & $51.4 \%$ & $64.7 \%$ & \\
\hline \multirow[t]{3}{*}{ District } & Dale & 128 & $26.7 \%$ & $35.5 \%$ & $38.2 \%$ & 0.480 \\
\hline & Hawassa & 128 & $39.0 \%$ & $31.4 \%$ & $29.4 \%$ & \\
\hline & Shebedino & 128 & $34.3 \%$ & $33.1 \%$ & $32.4 \%$ & \\
\hline \multirow[t]{2}{*}{ Feeding } & Grazing only & 127 & $61.9 \%$ & $24.1 \%$ & $8.8 \%$ & 0.000 \\
\hline & Supplemented & 257 & $38.1 \%$ & $75.9 \%$ & $91.2 \%$ & \\
\hline \multirow[t]{2}{*}{ Housing } & Indoor & 349 & $86.7 \%$ & $92.7 \%$ & $91.2 \%$ & 0.204 \\
\hline & Outdoor & 35 & $13.3 \%$ & $7.3 \%$ & $8.8 \%$ & \\
\hline
\end{tabular}

The overall prevalence of skin problems, taking into consideration sores, branded scar, hyena bite, donkey bite, ectoparasites, epizootic lymphangitis, sarcoid, dermatophytosis, abscess and ulcer due to Habronema, was $91.9 \%$. Sores were the most frequent (82.3\%) skin problems followed by ectoparasites (22.1\%) (Table 3).

Table 3: Prevalence of skin problems in working donkeys in three districts of Sidama zone $(\mathrm{N}=384)$

\begin{tabular}{lccc}
\hline Skin related problems & Number affected & $\%$ & $\mathbf{9 5 \%} \mathbf{C I}$ \\
\hline Sore & 316 & 82.3 & $78.5-86.1$ \\
Branded scar & 16 & 4.2 & $2.2-6.2$ \\
Hyena bite & 7 & 1.8 & $0.5-3.2$ \\
Donkey bite & 18 & 4.7 & $2.6-6.8$ \\
Ectoparasites & 85 & 22.1 & $18.0-26.3$ \\
Epizootic lymphangitis & 3 & 0.8 & $0.0-1.7$ \\
Sarcoid & 17 & 4.4 & $2.4-6.8$ \\
Dermatophytosis & 3 & 0.8 & $0.0-1.7$ \\
Abscess & 13 & 3.4 & $1.6-5.2$ \\
Habronema ulcer & 10 & 2.6 & $1.0-4.2$ \\
Overall & 353 & 91.9 & $89.2-94.7$ \\
\hline
\end{tabular}


Prevalence of sore was significantly associated $(P<0.001)$ with body condition and age of the donkeys and harness material and harness fitness. Accordingly, high prevalence of sore was observed in donkeys with poor body condition $(95.2 \%)$ as compared to donkeys with moderate $(80.4 \%)$ and ideal $(55.9 \%)$ body condition score. Old donkeys (91.1\%) were frequently affected compared to adults (82.3\%) and young (66.7\%). Donkeys with synthetic harness materials (89.1\%) were found more affected with sores as compared to donkeys with harness made up of natural materials (53.4\%). Donkeys with ill-fitted harness (86.3\%) were likely to suffer from sores than their counterparts (54.2\%). Use of donkeys as cart or pack animal, feeding, housing at night and district had no significant association with sore prevalence $(P>0.05)$ (Table 4$)$.

Table 4: Prevalence of sore in working donkeys in three districts of Sidama zone by main factors

\begin{tabular}{|c|c|c|c|c|c|c|}
\hline Factors & Category & $\begin{array}{l}\text { Number } \\
\text { examined }\end{array}$ & $\begin{array}{l}\text { Number } \\
\text { affected }\end{array}$ & $\%$ & $95 \% \mathrm{CI}$ & $P$ value \\
\hline \multirow[t]{3}{*}{$\mathrm{BCS} *$} & Poor & 105 & 100 & 95.2 & 91.1-99.3 & 0.000 \\
\hline & Moderate & 245 & 197 & 80.4 & $75.4-85.4$ & \\
\hline & Ideal & 34 & 19 & 55.9 & $38.9-72.9$ & \\
\hline \multirow[t]{3}{*}{ Age } & Young & 69 & 46 & 66.7 & $55.4-77.9$ & 0.000 \\
\hline & Adult & 192 & 158 & 82.3 & $76.9-87.7$ & \\
\hline & Old & 123 & 112 & 91.1 & $86.0-96.1$ & \\
\hline \multirow[t]{2}{*}{ Use } & Cart & 195 & 166 & 85.1 & $80.1-90.2$ & 0.139 \\
\hline & Pack & 189 & 150 & 79.4 & $73.6-85.2$ & \\
\hline \multirow{2}{*}{$\begin{array}{l}\text { Harness } \\
\text { materials }\end{array}$} & Natural & 73 & 39 & 53.4 & $41.9-65.0$ & 0.000 \\
\hline & Synthetic & 311 & 277 & 89.1 & $85.6-92.6$ & \\
\hline \multirow{2}{*}{$\begin{array}{l}\text { Harness } \\
\text { fitness }\end{array}$} & Fit & 48 & 26 & 54.2 & 39.9-68.5 & 0.000 \\
\hline & Ill-fit & 336 & 290 & 86.3 & $82.6-90.0$ & \\
\hline \multirow[t]{2}{*}{ Feeding } & Grazing only & 127 & 107 & 84.3 & 77.9-90.6 & 0.479 \\
\hline & Supplemented & 257 & 209 & 81.3 & $76.5-86.1$ & \\
\hline \multirow[t]{2}{*}{ Housing } & Indoor & 349 & 282 & 80.8 & $76.7-85.0$ & 0.016 \\
\hline & Out door & 35 & 34 & 97.1 & $91.5-100$ & \\
\hline \multirow[t]{3}{*}{ District } & Dale & 128 & 110 & 85.9 & $79.9-92.0$ & 0.336 \\
\hline & Hawassa & 128 & 105 & 82.0 & $75.3-88.7$ & \\
\hline & Shebedino & 128 & 101 & 78.9 & $71.8-86.0$ & \\
\hline
\end{tabular}

Ethiop. Vet. J., 2016, 20 (2), 99-118 
Sores were most frequent on body regions which come in contact with loads and harnesses. Accordingly withers/spine (179, 46.6\%), tail base (107, 27.9\%), lips $(81,21.1 \%)$, thighs $(80,20.8 \%)$ and girth $(71,18.5 \%)$ were the most affected (Table 5).

Table 5: Prevalence of sore on different body parts in cart and pack donkeys in Sidama zone $(\mathrm{N}=384)$

\begin{tabular}{|c|c|c|c|c|}
\hline \multirow[t]{2}{*}{ Body part } & \multirow{2}{*}{$\begin{array}{c}\text { Number } \\
\text { with sore } \\
(\%)\end{array}$} & \multicolumn{2}{|c|}{ Number (\%) } & \multirow[t]{2}{*}{$P$ value } \\
\hline & & $\operatorname{Cart}(n=195)$ & Pack $(n=189)$ & \\
\hline Face & $10(2.6)$ & $4(2.1)$ & $6(3.2)$ & 0.490 \\
\hline Lip & $81(21.1)$ & $70(35.9)$ & $11(5.8)$ & 0.000 \\
\hline Ear/ear base & $25(6.5)$ & $15(7.7)$ & $10(5.3)$ & 0.340 \\
\hline Neck & $19(4.9)$ & $9(4.6)$ & $10(5.3)$ & 0.760 \\
\hline Breast/shoulder & $39(10.2)$ & $34(17.4)$ & $5(2.6)$ & 0.000 \\
\hline Fore leg & $13(3.4)$ & $6(3.1)$ & $7(3.7)$ & 0.734 \\
\hline Wither/spine & $179(46.6)$ & 109 (55.9) & $70(37.0)$ & 0.000 \\
\hline Ribs/flank & $39(10.2)$ & $33(16.9)$ & $6(3.2)$ & 0.000 \\
\hline Girth/belly & $71(18.5)$ & $43(22.1)$ & $28(14.8)$ & 0.068 \\
\hline Thighs/buttocks & $80(20.8)$ & $47(24.1)$ & $33(17.5)$ & 0.109 \\
\hline Hind legs & $23(6.0)$ & $15(7.7)$ & $8(4.2)$ & 0.153 \\
\hline Tail base & $107(27.9)$ & $14(7.2)$ & $93(49.2)$ & 0.000 \\
\hline
\end{tabular}

Wither/spine (back) sore was by far the most important sore observed in the study (Table 5). Back sore was associated $(P<0.001)$ with body condition, housing, age, type of use, harness material, harness fitness, padding material and district (Table 6 ). High prevalence was associated with padding (53.5\% vs. $8.5 \%)$ and harness (54.0\% vs. $15.1 \%)$ made up of synthetic materials compared to use of natural materials. Back sore was highest in donkeys with poor body condition (78.1\%) compared to those with moderate (53.5\%) and ideal (17.6\%) body conditions. Donkeys which spend the night outdoor (88.6\%) were likely to suffer from back sore than donkeys kept indoor (42.4\%). Old (60.2\%) and adult (45.3\%) donkeys suffer more with back sore than young (26.1\%) donkeys. Back sore was more prevalent in donkeys used to pull cart (55.9\%) than donkeys used to carry pack (37.0\%). Donkeys in Hawassa (60.9\%) suffered a lot from back sore compared to donkeys in Dale (35.9\%) and Shebedino (43.0\%). 
Table 6: Prevalence of back (wither/spine) sore in working donkeys in three districts of Sidama zone by risk

\begin{tabular}{|c|c|c|c|c|c|c|}
\hline Factor & Category & $\begin{array}{c}\text { Number } \\
\text { examined }\end{array}$ & $\begin{array}{l}\text { Number } \\
\text { affected }\end{array}$ & $\%$ & $95 \% \mathrm{CI}$ & $P$ value \\
\hline \multirow{2}{*}{$\begin{array}{l}\text { Padding } \\
\text { material }\end{array}$} & Natural & 59 & 5 & 8.5 & $1.3-15.7$ & 0.000 \\
\hline & Synthetics & 325 & 174 & 53.5 & $48.1-59.0$ & \\
\hline \multirow[t]{3}{*}{ BCS } & Poor & 105 & 82 & 78.1 & $70.1-86.1$ & 0.000 \\
\hline & Moderate & 245 & 91 & 37.1 & 31.1-43.2 & \\
\hline & Ideal & 34 & 6 & 17.6 & $4.6-30.7$ & \\
\hline \multirow[t]{2}{*}{ Feeding } & Grazing only & 127 & 68 & 53.5 & $44.8-62.3$ & 0.056 \\
\hline & Supplemented & 257 & 111 & 43.2 & $37.1-49.3$ & \\
\hline \multirow[t]{2}{*}{ Housing } & Indoor & 349 & 148 & 42.4 & $37.2-47.6$ & 0.000 \\
\hline & Outdoor & 35 & 31 & 88.6 & 77.8-99.3 & \\
\hline \multirow[t]{3}{*}{ Age } & Young & 69 & 18 & 26.1 & $15.6-36.6$ & 0.000 \\
\hline & Adult & 192 & 87 & 45.3 & $38.2-52.4$ & \\
\hline & Old & 123 & 74 & 60.2 & 51.4-68.9 & \\
\hline \multirow[t]{2}{*}{ Use } & Cart & 195 & 109 & 55.9 & $48.9-62.9$ & 0.000 \\
\hline & Pack & 189 & 70 & 37.0 & $30.1-44.0$ & \\
\hline \multirow{2}{*}{$\begin{array}{l}\text { Harness } \\
\text { material }\end{array}$} & Natural & 73 & 11 & 15.1 & $6.8-23.4$ & 0.000 \\
\hline & Synthetic & 311 & 168 & 54.0 & $48.5-59.6$ & \\
\hline \multirow{2}{*}{$\begin{array}{l}\text { Harness } \\
\text { fitness }\end{array}$} & Fit & 48 & 6 & 12.5 & $3.0-22.0$ & 0.000 \\
\hline & Ill fit & 336 & 173 & 51.5 & $46.1-55.9$ & \\
\hline \multirow[t]{3}{*}{ District } & Dale & 128 & 46 & 35.9 & $27.6-44.3$ & 0.000 \\
\hline & Hawassa & 128 & 78 & 60.9 & 52.4-69.4 & \\
\hline & Shebedino & 128 & 55 & 43.0 & $34.3-51.6$ & \\
\hline
\end{tabular}

There was no statistically significant difference $(P>0.05)$ in prevalence of sore on face, ear/ear base, neck, foreleg, girth, thighs/buttocks and hind leg of donkeys used as cart and pack animals. Cart donkeys had higher prevalence of sore $(P<0.001)$ on their lips, breast/shoulder, wither/spine and ribs/flank compared to pack donkeys. However donkeys used to carry packs on their back had a higher prevalence $(P<0.001)$ of sore at their tail base (Table 5$)$.

Ectoparasites were found to be the second frequent dermatological conditions in donkeys only next to sore (Table 3). The overall prevalence of ectoparasites in 
donkeys in this study was $22.1 \%$. The ectoparasites identified were lice (11.2\%), ticks $(10.4 \%)$ and mange mites $(1.6 \%)$, with mixed infestation involving lice and ticks in $3(0.8 \%)$ donkeys. Hematopinus $(7.0 \%)$ and Damalinia $(4.2 \%)$ were the genera of lice identified, while Amblyomma, Rhipicephalus and Boophilus were the genera of ticks found infesting donkeys with $6.3 \%, 2.1 \%$ and $2.1 \%$ prevalence respectively. Among mange mites Sarcoptes, Psoroptes and Chorioptes were identified with $0.3 \%, 0.8 \%$ and $0.5 \%$ prevalence, respectively (Table 7).

Table 7: Prevalence of ectoparsites on working donkeys in 3 districts of Sidama zone $(\mathrm{N}=384)$

\begin{tabular}{lccc}
\hline Ectoparasites & Number affected & \% & $\mathbf{9 5 \%}$ CI \\
\hline Overall & 85 & 22.1 & $18.0-26.3$ \\
Lice & 43 & 11.2 & $8.0-14.4$ \\
Damalinia & 16 & 4.2 & $3.0-6.2$ \\
Hematopinus & 27 & 7.0 & $4.9-10.2$ \\
Ticks & 36 & 10.4 & $7.3-13.5$ \\
Amblyomma & 24 & 6.3 & $3.8-8.7$ \\
Boophilus & 8 & 2.1 & $0.6-3.5$ \\
Rhipicephalus & 8 & 2.1 & $0.6-3.5$ \\
Mange mites & 6 & 1.6 & $0.3-2.8$ \\
Sarcoptes & 1 & 0.3 & $0.0-0.8$ \\
Psoroptes & 3 & 0.8 & $0.0-1.7$ \\
Chorioptes & 2 & 0.5 & $0.2-1.2$ \\
\hline
\end{tabular}

There was a statistically significant association $(P<0.05)$ between the prevalence of lice infestation and body condition, age, feeding, housing and district. High prevalence of lice was observed in donkeys with poor body condition (24.8\%) than donkeys with moderate (6.9\%) and ideal (0\%) body condition. Old donkeys (17.1\%) had highest prevalence of lice than adult (9.9\%) and young (4.3\%) donkeys. Lice infestation was high in donkeys which were kept indoor (11.5\%) during the night and donkeys which were kept on grazing alone (15.0\%) compared to their counterparts. The highest lice infestation was observed in Shebedino (16.4\%) followed by Dale (10.2\%) while donkeys in Hawassa had the smallest prevalence (4.7\%). All the donkeys found infested with lice were from those which are kept indoor during the night. However there was no statistically significant association $(P>0.05)$ between prevalence of lice infestation and use of donkeys as a cart or pack animal (Table 7). 
Infestation with ticks was also significantly influenced by district and the type of housing during the night $(P<0.05)$. Similar to lice, donkeys in Shebedino (16.4\%) suffered the highest infestation with ticks while donkeys in Hawassa (4.7\%) suffered the least. All the donkeys affected with ticks were those kept indoor during the night, i.e. no donkey among those kept outdoor during the night was infested with ticks. Tick infestation, however, had no association $(P>0.05)$ with age and use of donkeys (Table 8$)$. No statistical association ( $P$ $>0.05$ ) was found between mange mite prevalence and all the factors considered in our study (Table 8).

Table 8: Prevalence of lice, mange mites and ticks in relation to body condition score (BCS), age, use, feeding, district and housing of donkeys

\begin{tabular}{|c|c|c|c|c|c|c|c|c|}
\hline \multirow{2}{*}{$\begin{array}{l}\text { Risk } \\
\text { factor }\end{array}$} & \multirow[t]{2}{*}{ Category } & \multirow[t]{2}{*}{ Number } & \multicolumn{2}{|c|}{ Lice } & \multicolumn{2}{|c|}{ Tick } & \multicolumn{2}{|c|}{ Mange mite } \\
\hline & & & $\%$ & $P$ value & $\%$ & $P$ value & $\%$ & $\begin{array}{c}P \\
\text { value }\end{array}$ \\
\hline \multirow[t]{3}{*}{$\mathrm{BCS}$} & Poor & 105 & 24.8 & 0.000 & 10.5 & 0.106 & 3.8 & 0.087 \\
\hline & Moderate & 245 & 6.9 & & 11.4 & & 0.8 & \\
\hline & Ideal & 34 & 0 & & 0 & & 0 & \\
\hline \multirow[t]{3}{*}{ Age } & Young & 69 & 4.3 & 0.020 & 5.8 & 0.353 & 0 & 0.487 \\
\hline & Adult & 192 & 9.9 & & 12.0 & & 2.1 & \\
\hline & Old & 123 & 17.1 & & 10.6 & & 1.6 & \\
\hline \multirow[t]{2}{*}{ Use } & Cart & 195 & 7.2 & 0.059 & 9.2 & 0.440 & 1.0 & 0.389 \\
\hline & Pack & 189 & 13.8 & & 11.6 & & 2.1 & \\
\hline \multirow[t]{2}{*}{ Feeding } & Grazing only & 127 & 15.0 & 0.040 & 12.6 & 0.265 & 3.1 & 0.078 \\
\hline & Supplemented & 257 & 8.2 & & 8.9 & & 0.8 & \\
\hline \multirow[t]{3}{*}{ District } & Dale & 128 & 10.2 & 0.009 & 9.4 & 0.008 & 1.6 & 0.131 \\
\hline & Hawassa & 128 & 4.7 & & 4.7 & & 0 & \\
\hline & Shebedino & 128 & 16.4 & & 16.4 & & 3.1 & \\
\hline \multirow[t]{2}{*}{ Housing } & Indoor & 349 & 11.5 & 0.034 & 11.2 & 0.037 & 1.7 & 0.434 \\
\hline & Outdoor & 35 & 0 & & 0 & & 0 & \\
\hline
\end{tabular}

Sarcoid was identified by the study as one of the most important dermatological problems in donkeys with $4.4 \%$ prevalence (Table 3). Sarcoid prevalence was significantly $(P<0.001)$ associated with age and body condition of the donkeys. Young donkeys less than 5 years old had the highest prevalence of sarcoid (23.2\%) compared to adult (0.5\%) and old (0\%) donkeys. All sarcoid cases observed in the study belonged to donkeys with moderate body condition. All 
other factors considered in the study, however, had no association with sarcoid prevalence $(\mathrm{P}>0.05)$ (Table 9$)$.

Table 9: Prevalence of sarcoid by age, BCS, housing, feeding, use, district and harness material

\begin{tabular}{|c|c|c|c|c|c|c|}
\hline Risk factor & Category & $\begin{array}{l}\text { Number } \\
\text { examined }\end{array}$ & $\begin{array}{l}\text { Number } \\
\text { affected }\end{array}$ & $\%$ & CI & $P$ value \\
\hline \multirow[t]{3}{*}{ Age } & Young & 69 & 16 & 23.2 & $13.1-33.1$ & 0.000 \\
\hline & Adult & 192 & 1 & 0.5 & $0-1.5$ & \\
\hline & Old & 69 & 0 & 0 & - & \\
\hline \multirow[t]{3}{*}{ BCS } & Poor & 105 & 0 & 0 & & 0.006 \\
\hline & Moderate & 245 & 17 & 6.9 & $3.7-10.1$ & \\
\hline & Ideal & 34 & 0 & 0 & & \\
\hline \multirow[t]{2}{*}{ Housing } & Indoor & 349 & 17 & 4.9 & $2.6-7.2$ & 0.182 \\
\hline & Outdoor & 35 & 0 & 0 & & \\
\hline \multirow[t]{2}{*}{ Feeding } & Grazing only & 127 & 4 & 3.1 & $0.1-6.2$ & 0.392 \\
\hline & Supplemented & 257 & 13 & 5.1 & $2.4-7.8$ & \\
\hline \multirow[t]{2}{*}{ Use } & Cart & 195 & 7 & 3.6 & $1.0-6.2$ & 0.418 \\
\hline & Pack & 189 & 10 & 5.3 & $2.1-8.5$ & \\
\hline \multirow[t]{3}{*}{ District } & Dale & 128 & 6 & 4.7 & $1.0-8.4$ & 0.103 \\
\hline & Hawassa & 128 & 2 & 1.6 & $0-3.7$ & \\
\hline & Shebedino & 128 & 9 & 7.0 & $2.6-11.5$ & \\
\hline \multirow{2}{*}{$\begin{array}{l}\text { Harness } \\
\text { material }\end{array}$} & Natural & 73 & 4 & 5.5 & $0.2-10.8$ & 0.627 \\
\hline & Synthetic & 311 & 13 & 4.2 & $1.9-6.4$ & \\
\hline \multirow{2}{*}{$\begin{array}{l}\text { Harness } \\
\text { fitness }\end{array}$} & Fit & 48 & 1 & 2.1 & $0-6.2$ & 0.399 \\
\hline & Ill fit & 336 & 16 & 4.8 & $2.5-7.0$ & \\
\hline
\end{tabular}

\section{Discussion}

The current study found that only less than $10 \%$ of the working donkeys were with ideal body condition, and over a quarter (27.3\%) was with poor body condition. This may suggest either neglect in the management of working donkeys or neediness of the people working with them. The owners may not afford feeding the donkeys with concentrate as this may compete with household expenditures or they may not afford resting the animals which in turn limits grazing time and prolong working hours with serious nutritional 
consequences and exhaustion. Old age, above 15 years, and use of donkeys for cart and keeping donkeys mainly on grazing were associated with poor body condition. Cart donkeys are likely to carry heavy loads, work for many days a week and long hours a day compared to pack donkeys; therefore are prone to exhaustion and body condition loss.

Our data identified that most harnesses and padding were made up of synthetic materials and most harnesses were ill-fitted to the donkeys and these factors were found associated with high sore prevalence. This finding supports the statement by Pearson et al. (2003) where padding and harnessing with synthetic materials such as plastics and nylon was associated with sores.

The study revealed that very large proportions of working donkeys in the study area were affected by a range of skin problems. High prevalence $(88.8 \%)$ of skin injuries (sore, hyena and donkey bite) was recorded in the present study. Demelash Biffa and Moges Woldemeskel (2006) similarly reported a high level of (79.4\%) skin injury in working donkeys in Hawassa. The same work identified that improper harness and saddle design were the most important causes of injuries in both horses and donkeys.

Skin sore was the most important problem (82.3\%) in donkeys examined in the current study. Agajie Tesfaye and Curran (2005) reported back sores as the most commonly observed health problems in donkeys in central Ethiopia. The presence of conditions which are likely to increase the chances of working equines to suffer from harness associated sores, such as lack of awareness about improved harnessing and saddling techniques, lack of rest for donkeys with back sore and little attention about the health of donkeys, have been reported in Ethiopia (Agajie Tesfaye and Curran, 2005; Demelash Biffa and Moges Woldemeskel, 2006).

The current study demonstrated association between use of synthetic harnessing and padding materials and ill-fitted harness and high prevalence of sores in donkeys. A poorly designed or ill-fitted harness can cause injury to the animal (Pearson et al., 2003; Demelash Biffa and Moges Woldemeskel, 2006). Pearson et al. (2003) recommend the use of natural materials such as cotton and wool instead of synthetic materials such as nylon and plastic for harness and padding in order to reduce injury to working animals. Sores were also 
associated with body condition. Animals in good condition have good muscle and even some fat on their back which can act as natural cushion (Pearson et al., 2003). Sores were most frequent on body parts which come in contact with loads and harnesses suggesting that they were work associated.

The occurrence of back sores indicated in the current study is in agreement with earlier report (Agajie Tesfaye and Curran, 2005) being the most common cause of health problem in donkeys in central Ethiopia. High proportion of back sore was observed on cart than pack donkeys. Cart donkeys may develop back sore more frequently, compared to those used for pack purpose, because they face heavier workload, work for more days a week and usually work for long hours per day. Moreover, cart donkeys are usually kept for income generation as opposed to pack donkeys which are used mainly for owners' household needs. It may also be related to the difference in the harnesses used for cart and pack donkeys.

The overall prevalence of ectoparasites recorded during this study was lower than the prevalence observed in Meskan district, southern Ethiopia by Solomon Mekuria and Rahmeto Abebe (2010). Prevalence of ticks recorded in the present study (10.4\%) was also much lower compared to the prevalence (32\%) reported from central Ethiopia (Beshatu Ferede et al., 2010). This difference may be accounted to the variation in agro-climatic conditions and management systems of animals among the study areas. The prevalence of tick infestation and species composition has been reported to be influenced by variation in altitude (Bekele Tafesse, 1996).

Three genera of ticks, Amblyomma, Rhipicephalus and Boophilus, were recorded in the current study. This was in agreement with the work of Beshatu Ferede et al. (2010) where they reported the prevalence of all these genera plus Hyalomma from central Ethiopia. Tick prevalence was affected by district and whether the donkeys were kept indoor or outdoor at night. Prevalence was highest in Shebedino followed by Dale and lowest in Hawassa. The reasons for the differences in prevalence among the localities probably are variations in agro-ecology, type of use of donkeys, feeding and other animal management practices. Donkeys in Hawassa, where ectoparasites prevalence was low, were mostly cart donkeys and were supplemented (data not presented). Donkeys used as pack animals mostly spend longer hours on pasture, probably with other species of livestock, and are likely to get infested with ticks. 
Lice infestation is a concern in donkeys under the current study. Old donkeys, donkeys with poor body condition, non-supplemented donkeys and donkeys kept indoors at night had high prevalence of lice infestation compared to their counterparts. In line with our finding, Trawford and Getachew Mulugeta (2008) indicated that young donkeys of less than 3 years age and older donkeys with poor body condition usually have heaviest lice burden. Old age and poor nutrition often lead to weakness and poor body condition. Animals which are debilitated for any reason and unable to groom themselves are prone to lice infestation (Urquart, 1996). The fact that lice were observed only in donkeys kept in door during the night may be explained by the lifecycle of the parasite.

Lice are permanent parasites which cannot survive for long away from the host and therefore need close contact for transmission (Urquart, 1996) which is more possible in a confined environment. Lice are common in groups of closely managed donkeys (Knottenbelt, 2008). Lice infestation was also influenced by locality. The most probable reason for this is difference in agro-ecology of the localities. Shebedino and Dale districts where the lice prevalence was higher lie at higher altitude than Hawassa. Higher prevalence of lice in high altitudes than in lower altitudes in sheep and goats in Ethiopia has been described (Tefera Sertse and Abebe Wossene, 2007). Dense lice infestations are commonly observed during cooler periods (Trawford and Getachew Mulugeta, 2008).

The mange mites identified in this study includes Psoroptes, Chorioptes and Sarcoptes species. Osman et al. (2006) similarly identified these three genera of mange mites in drafting horses in Egypt. Chorioptes mites are reported to be the most important causes of equine mange (Curtis, 1999; Osman et al., 2006). Psoroptic mange has also been reported as cause of mange in donkeys (ABU -SAMARA et al., 1987) and horses (Osman et al., 2006).

The prevalence of epizootic lymphangitis $(0.78 \%)$ observed in the present study was lower compared to the prevalence recorded in carthorses $(12.3 \%)$ in Hawassa (Gobena Ameni, 2006). This is perhaps because donkeys are apparently more resistant to epizootic lymphangitis (Jones, 2006), although the disease occurs in them (Knottenbelt, 2008). Epizootic lymphangitis is prevalent in carthorses in hot and humid Ethiopian towns with an altitude ranging from 1500 to 2300 meters above sea level (Gobena Ameni, 2006). 
High prevalence of sarcoid was observed on young donkeys than adults and old donkeys. Sarcoid is by far the commonest skin tumour of the donkey (Knottenbelt, 2008) and epidemiological observation on sarcoid in a population of 4126 donkeys in the donkey sanctuary, UK, had indicated that the disease most frequently occurs in younger, male donkeys in their first five years of age (Reid et al., 1994).

The study demonstrated a high prevalence of skin associated problems in donkeys in the study area. The overall prevalence of skin problems, especially sores, recorded in this study presents a concern regarding health and welfare state of majority of working donkeys in the study area and a possible disregard in their management. As these animals are means of livelihood for many people in the study area, compromise in their welfare and health has got major socio-economic implications for the people who depend on them. Proper training regarding the selection and proper use of harness materials, proper feeding and health care of working donkeys is required to donkey owners and attendants in order to reduce the prevalence of skin lesions.

\section{Conclusion}

The study revealed a high prevalence of skin problems in general and sores in particular which suggest profound compromise in welfare and health of the animals and possible neglect by their owners. Efforts should be made to increase the awareness of the community in general and donkey owners in particular towards improving animal welfare and health.

\section{Acknowledgments}

The cooperation of owners/attendants of the donkeys is gratefully acknowledged. We also appreciate the all-round help of the Donkey Sanctuary Ethiopia, Hawassa branch for the success of this study.

\section{References}

Abu-Samra, M.T., Abbas, B. and Ibrahim, K.E.E., 1987. Five cases of psoroptic mange in the domestic donkey (Equus asinus asinus) and treatment with ivermectin. Equine Vet. J., 19(2), 143-144. 
Ameni, G., 2006. Epidemiology of equine histoplasmosis (epizootic lymphangitis) in carthorses in Ethiopia. Vet. J., 172(1), 160-165.

Anonymous, 1999. Annual report, Sidama Zone Agriculture and Rural Development Department.

Anonymous, 2004. Socio-economic and demographic profile of Sidama zone (SEDPSZ). Finance and economic development coordination department, Awassa, Ethiopia.

Biffa, D. and Woldemeskel, M., 2006. Causes and factors associated with occurrence of external injuries in working equines in Ethiopia, Int. J. Appl. Res. Vet. Med., 4(1), 3-5.

CSA, 2012. Federal Democratic Republic of Ethiopia, Central Statistical Agency (CSA), Agricultural Sample Survey 2011/12 (2004 E.C.), Volume II. Report on livestock and livestock characteristics (private peasant holdings). Statistical Bulletin 532, March 2012, Addis Ababa.

Crane, M., 1997. Medical. In: E.D. Svendsen (ed). The Professional Handbook of the Donkey ( $3^{\text {rd }}$ ed). Whittet Books Limited. London. pp. 19-36.

Curtis, C.F., 1999. Pilot study to investigate the efficacy of a 1 per cent selenium sulphide shampoo in the treatment of equine chorioptic mange. Vet. Rec., 144(24), 674-675.

Ferede, B., Kumsa, B., Bsrat, A. and Kalayou, S., 2010. Ticks of donkeys in central Oromia regional state, Ethiopia. Rev. Med. Vet., 161(3), 121-126.

Gebreab, F., Gebrewold, A., Kelemu, F., Ibro, A. and Yilma, K., 2004. Donkey utilisation and management in Ethiopia. In: D. Fielding and P. Starkey (Eds.). Donkeys, People and Development. A resource book of the Animal Traction Network for Eastern and Southern Africa (ATNESA). ACP-EU Technical Centre for Agricultural and Rural Cooperation (CTA), Wageningen, The Netherlands. pp 46-52.

Gebrewold, A., Tegegn, A. and Yami, A., 2004. Research needs of donkey utilisation in Ethiopia. In: D. Fielding and P. Starkey (Eds.). Donkeys, People and Development. A resource book of the Animal Traction Network for Eastern and Southern Africa (ATNESA). ACP-EU Technical Centre for Agricultural and Rural Cooperation (CTA), Wageningen, The Netherlands. pp 77-81.

Jones, K., 2006. Epizootic lymphangitis: The impact on subsistence economies and animal welfare. Vet. J., 172(3), 402-404.

Jones, P.A., 2005. Donkeys for Development, New edition, p.4158

Knottenbelt, D.C., 2008. Skin disorders. In: E. D. Svendesen (Ed).The professional handbook of the donkey ( $\left.4^{\text {th }} \mathrm{ed}\right)$, Whitteet Book limited. London, pp. 124-152. 
Knottenbelt, D.C., 2009. Pascoe's Principles and Practice of Equine Dermatology, 2nd ed, Elsevier Health Sciences. p.520

Mekuria, S. and Abebe, R., 2010. Observation on major welfare problems of equine in Meskan district, Southern Ethiopia, Livestock Research for Rural Development, 22 (3).

NEWC (National Equine Welfare Council), 2009. Equine Industry Welfare Guidelines Compendium for Horses, Ponies and Donkeys, $3^{\text {rd }}$ edition. pp. 55-56.

Osman, S.A., Hanafy, A. and Amer, S.E., 2006. Clinical and therapeutic studies on mange in horses, Vet. Parasitol., 141(1), 191-195.

Pearson, R.A., Simalenga, T.E. and Krecek, R.C., 2003. Harnessing and hitching donkey horses and mules for work. Centre for Tropical Veterinary Medicine, University of Edinburgh, pp. 34

Quinn, P.J., Carter, M.E., Markey, B.K. and Carter, G.R., 1999. Clinical Veterinary Microbiology, Elsevier Ltd, p.565.

Reid, S.W., Gettinby, G., Fowler, J. N. and Ikin, P., 1994. Epidemiological observations on sarcoids in a population of donkeys (Equus asinus), Vet. Rec., 134(9), 207-211.

Sertse, T. and Wossene, A., 2007. A study on ectoparasites of sheep and goats in eastern part of Amhara region, northeast Ethiopia. Small Ruminant Res., 69, 62-67.

Tafesse, B., 1996. Survey on the distribution of ticks of domestic animals in the eastern zone of Ethiopia, Trop. Anim. Health Prod., 28, 145-146.

Tesfaye, A. and Curran, M.M., 2005. A longitudinal survey of market donkeys in Ethiopia. Trop. Anim. Health Prod., 37(1), 85-100.

Trawford, A. and Mulugeta, G., 2008. Parasites. In: Svendesen, E.D., (Ed). The professional handbook of the donkey ( $4^{\text {th }}$ ed), Whitteet Book limited, London, pp. 82-110.

Urquhart, G.M., Armour, J., Duncan, J.L., Dunn, A.M. and Jennings, F.W., 1996. Veterinary Parasitology, $2^{\text {nd }}$ ed, Blackwell Science Ltd., UK, p. 307.

Walker, A.R., Bouattour, A., Camicas, J.-L., Estrada-Pena, A., Horak, I.G., Latif, A.A., Pegram, R.G. and Preston, P.M., 2003. Ticks of Domestic Animals in Africa, A Guide to Identification of Species. International Consortium on Ticks and Tickborne Diseases (ICTTD-2), Bioscience Reports, The University of Edinburgh, UK, p.221.

Wall, R. and Shearer, D., 1997. Veterinary Entomology: Arthropod ectoparasites of veterinary importance, $1^{\text {st }}$ ed, Chapman and Hall, p. 456. 